\title{
Editorial
}

\section{Improving access to health care for lesbian, gay and bisexual people.}

\author{
Henrique Pereira \\ Department of Psychology and Education \& Health Sciences Research Centre, University of Beira Interior Rua Marques D’Ávila e \\ Bolama, 6200 - Covilhã, Portugal
}

\section{Introduction}

Despite growing acceptance of same-sex sexuality in western countries (Costa, Pereira \& Leal 2014) and recent political and legislative changes in many of them - such as laws allowing same-sex couples to marry and adopt or joint-adopt children, lesbian, gay and bisexual (LGB) individuals still face prejudice in society mostly due to religious conservatism and right-wing political positioning (Commissioner for Human Rights 2011; Costa et al. 2014; Costa et al. 2015). Consequently, the identity development of LGB individuals is restricted by these negative societal attitudes, which may perpetuate the experience of stigmatization and social discrimination (Rankin et al. 2010). Minority stress theory suggests that stigma and interpersonal discrimination are risk factors for physical and mental health problems among sexual minorities (Pereira \& Costa 2016; Lyons \& Hosking 2014; Woodford et al. 2014).

\section{LGB Health Disparities}

Consistent with the minority stress theory, research generally finds a positive association between interpersonal discrimination and poor physical and mental health outcomes among sexual minorities including: HIV risk and infection, and sexually transmitted infections (Ayala et al. 2012; Beyrer et al. 2012; Lyons, Pitts \& Grierson 2012; Pereira 2014; Wolitski \& Fenton 2011); higher rates of tobacco smoking and illicit drug use (Rivers 2001; Willoughby et al. 2008; Drabble et al. 2005); use of methamphetamine and other "party drugs" (Gonzales, Mooney \& Rawson, 2010; Halkitis, Palamar \& Mukherjee 2007; Lyons, Pitts \& Grierson, 2013), and asthma, diabetes, cardiovascular disease, or disability (Dilley et al. 2010; Kim et al. 2012; Fredriksen-Goldsen et al. 2013; Farmer et al. 2013). In addition, rates of depression and anxiety are well above those of the heterosexual population (Bostwick et al. 2014; Chakraborty et al. 2011; Morrison 2011; Pereira \& Rodrigues 2015), as well as emotional distress (Almeida et al. 2009; Choi et al. 2013), self-esteem (Huebner, Rebchook \& Kegeles 2004), panic disorder (Mays \& Cochran 2001), suicide and suicide risk (Semp \& Read 2015; Haas et al. 2010; Pereira \& Rodrigues 2015; Thoma \& Huebner 2013), and this could be particularly the case for more vulnerable LGB people such as older LGB individuals (Addis et al. 2009; Harper \& Scheineder 2003; Jackson, Johnson \& Roberts 2008). Therefore, there are accumulating data indicating that health problems are more prevalent among sexual minorities than among heterosexuals.

The growing number of studies that have found clear disparities among sexual minority groups and straight populations raises public health concerns for the LGB community and the wider population (Campbell 2013). Also it is becoming more evident that, in many countries, LGB individuals are not able to exercise fully their rights to health care and service utilization because of discriminatory laws or anticipation of rejection by their health care providers (Conron et al. 2010; Boehmer 2012).

\section{Health Care access}

LGB individuals often face challenges and barriers to accessing needed health services and, as a result, can experience worse health outcomes. Lower rates of primary care utilization among LGB populations may be founded on expectations and experiences of stigma based on sexual orientation (Whitehead et al. 2016). The prevalence of measures of health care service utilization and access varies across categories of sexual orientation (Ward et al. 2014), translating into having less health insurances and having more irregular health providers (Conron et al. 2010; Gonzales \& Blewett 2014) or limitations on procreation and access to assisted reproductive technologies (Kissil \& Davey 2012). A continuum of five discourses that characterize the health services access by LGB people and equity literature were identified by Daley \& MacDonnell (2014) including two dominant discourses: 1) multicultural discourse, and 2) diversity discourse; and three counter discourses: 3) social determinants of health discourse; 4) anti-oppression discourse; and 5) citizen/social rights discourse.

In addition to the same health concerns as the general population, sexual minorities face higher rates of illness and health challenges, hence being more likely to experience obstacles in obtaining care. Barriers to care include the lack of advertisement of LGB-affirming providers, gaps in coverage, cost-related hurdles, poor treatment from health care providers (Kates et al. 2015), lack of information and negative attitudes of health-care providers (Blondeel et al. 2016; Sabin et al. 2015). Understanding these barriers and the additional health risks they impose is crucial to improving the health status of LGB individuals.

\section{Promoting Health Equity}

The primary focus in LGB health has been on disparities and the negative experiences LGB people may encounter. Glaringly absent in previous studies of LGB health has been attention to health equity and the more positive aspects of LGB health. A health-equity approach aims to reduce disparities and maximize efforts to reach full health capacity. Through a health equity perspective, our attention shifts to how LGB individuals can achieve a sense of well-being, enhanced quality of life, and attain their full health potential (Fredriksen-Goldsen et al. 2013).

In this paper, I have illustrated the importance of connecting to the health and wellbeing issues affecting sexually diverse people. Such connections now need to be acknowledged and 
applied in the development and implementation of public health policy. To date, many western states have failed to capture sexually diverse populations in health and social service public policies, despite evidence for numerous structurally-driven, population-based health disparities.

LGB people cross all socio-economic, ethno-racial, age, gender, (dis)ability, religious, geographical location, educational, and relationship status lines. Consequently, for many in these communities, their existence is made up of multiple intersecting social identities. These identities intersect and are affected by societal power dynamics that can result in oppressions and/or privileges that play out structurally or individually and interpersonally (Moosa-Mitha et al. 2005).

Recognition of oppressions and how they affect LGB populations and their social identities and health and wellbeing requires us to reframe population health, and public health goals to provide a stronger foundation for inclusive health promotion policies and initiatives that capture sexual diversity.

An important body of research using a variety of methodologies has consistently documented high levels of discrimination against LGB people (Fundamental Rights Agency 2014; Sears \& Mallory 2011), and demonstrates a consistent pattern: sexual orientation-based discrimination is common in many health settings. Furthermore, research shows that discrimination has negative impacts on LGB people in terms of physical and emotional health. Therefore, positive measures to promote respect for the human rights of lesbian, gay and bisexual people should be adopted and implemented everywhere.

\section{Conclusion}

There must be recognition of the unique and specific health and well-being issues affecting LGB people, substantiated with knowledge guided by a critical/structural analysis followed by implementation of funding, programming, and services, in which LGB individuals and communities can be represented in health policy (Mulé et al. 2009), prioritizing them in order to address their health and well-being concerns, implicating the diverse communities' voices and experiences; the health care and social service systems, that must reshape how they provide service delivery; and the broader society that needs to become knowledgeable and sensitized to these issues via public health education campaigns in order to combat homophobia and heterosexism directed at these populations.

\section{REFERENCES}

1. Almeida, J, Johnson, RM, Corliss HL, Molnar, BE \& Azrael, D 2009, 'Emotional distress among LGBT youth: The influence of perceived discrimination based on sexual orientation', Journal of Youth and Adolescence, vol. 38, pp. 1001-1014.

2. Ayala, G, Bingham, T, Kim, J, Wheeler, DP \& Millett, GA 2012, 'Modeling the impact of social discrimination and financial hardship on the sexual risk of HIV among Latino and Black men who have sex with men', American Journal of Public Health, vol. 102, no. S2, pp. S242-S249.
3. Beyrer, C, Baral, SD, van Griensven, F, Goodreau, SM, Chariyalertsak, S, Wirtz, AL \& Brookmeyer, R 2012, 'Global epidemiology of HIV infection in men who have sex with men', Lancet, vol. 380, pp. 367-377.

4. Blondeel, K, Say, L, Chou, D, Toskin, I, Khosla, R, Scolaro, E \& Temmerman M 2016, 'Evidence and knowledge gaps on the disease burden in sexual and gender minorities: a review of systematic reviews', International Journal for Equity in Health, vol. 15, no. 16.

5. Boehmer, U, Miao, X, Linletter, C \& Clark, MA 2012 , 'Adult health behaviors over the life course by sexual orientation', American Journal Public of Health, vol. 102, no. 2, pp. 292-300.

6. Bostwick, WB, Boyd, CJ, Hughes, TL, West, BT \& McCabe, SE 2014, 'Discrimination and mental health among lesbian, gay, and bisexual adults in the United States', American Journal of Orthopsychiatry, vol. 84, pp. 35-45.

7. Campbell, S 2013, 'Sexual health needs and the LGBT community', Nursing Standard, vol. 27, no. 32, pp. 35-38.

8. Chakraborty, A, McManus, S, Brugha, TS, Bebbington, P \& King, M 2011, 'Mental health of the non-heterosexual population of England', British Journal of Psychiatry, vol. 198, pp. 143-148.

9. Choi, KH, Paul, J, Ayala, G, Boylan, R \& Gregorich, SE 2013, 'Experiences of discrimination and their impact on the mental health among African-American, Asian and Pacific Islander, and Latino men who have sex with men', American Journal of Public Health, vol. 103, pp. 868-874.

10. Commissioner for Human Rights 2011, Discrimination on grounds of sexual orientation and gender identity in Europe, Council of Europe Publishing, Strasbourg, France.

11. Conron, KJ, Mimiaga, MJ \& Landers, SJ 2010, 'A population-based study of sexual orientation identity and gender differences in adult health', American Journal Public of Health, vol. 100, no. 10, pp. 1953-1960.

12. Costa, PA, Caldeira, S, Fernandes, I, Rita C, Pereira, H \& Leal, I 2014, 'Religious and political conservatism and beliefs about same-sex parenting in Portugal'. Psychology, Community \& Health, vol.3, pp. 23-35.

13. Costa, PA, Pereira H \& Leal, I 2015, "'The contact hypothesis" and attitudes toward same-sex parenting', Sexuality Research and Social Policy, vol.12, no. 2, pp 125-136.

14. Costa, PA, Pereira, H \& Leal, I 2013, 'Internalized Homonegativity, Disclosure, and Acceptance of Sexual Orientation in a Sample of Portuguese Gay and Bisexual Men, and Lesbian and Bisexual Women', Journal of Bisexuality, vol. 13, pp. 229-244.

15. Daley, AE \& MacDonnell, JA 2011, 'Gender, sexuality and the discursive representation of access and equity in health services literature: implications for LGBT communities', International Journal for Equity in Health, vol. 10, no. 40.

16. Dilley, JA, Simmons, KW, Boysun, MJ, Pizacani, BA \& Stark, MJ 2010, 'Demonstrating the importance and 
feasibility of including sexual orientation in public health surveys: Health disparities in the Pacific Northwest', American Journal Public of Health, vol. 100, no. 3, pp.460-467.

17. Drabble, L, Midanik, LT \& Trocki, K 2005, 'Reports of alcohol consumption and alcohol-related problems among homosexual, bisexual and heterosexual respondents: Results from the 2000 National Alcohol Survey', Journal of Studies of Alcohol, vol. 66, no. 1, pp. 111-120.

18. Farmer, GW, Jabson, JM, Bucholz, KK \& Bowen, DJ 2013, 'A population-based study of cardiovascular disease risk in sexual-minority women', American Journal Public of Health, vol. 103, no. 10, pp. 1845-1850.

19. FRA (European Union Agency for Fundamental Rights) 2014, 'EU LGBT Survey - European Union Lesbian, Gay, Bisexual and Transgender Survey: Main Results', Publications Office of the European Union, Luxembourg.

20. Fredriksen-Goldsen, KI, Kim, HJ, Barkan, SE, Muraco, A \& Hoy-Ellis, CP 2013 'Health disparities among lesbian, gay, and bisexual older adults: Results from a population-based study', American Journal Public of Health, vol. 103, no. 10, pp. 1802-1809.

21. Gonzales, G \& Blewett, LA 2014, 'National and StateSpecific Health Insurance Disparities for Adults in SameSex Relationships', American Journal of Public Health, vol. 104, no. 2, pp. 95-104.

22. Gonzales, R, Mooney, L \& Rawson, RA 2010, 'The methamphetamine problem in the United States', Annual Review of Public Health, vol. 31, pp. 385-398.

23. Haas, AP, Eliason, M, Mays, VM, Mathy, RM, Cochran, SD, D'Augelli, AR \& Clayton, PJ 2010, 'Suicide and suicide risk in lesbian, gay, bisexual, and transgender populations: Review and recommendations', Journal of Homosexuality, vol. 58 , pp. $10-51$.

24. Halkitis, PN, Palamar, JJ \& Mukherjee, PP 2007, 'Poly-clubdrug use among gay and bisexual men: A longitudinal analysis', Drug and Alcohol Dependence, vol. 89, pp. 153-160.

25. Huebner, DM, Rebchook, GM \& Kegeles, SM 2004, 'Experiences of harassment, discrimination, and physical violence among young gay and bisexual men', American Journal of Public Health, vol. 94, pp. 1200-1203.

26. Kates, J, Ranji, U, Beamesderfer, A, Salganicoff, A \& Dawson, L 2015, 'Health and Access to Care and Coverage for Lesbian, Gay, Bisexual, and Transgender Individuals in the U.S.', The Henry J. Kaiser Family Foundation

27. Kim, HJ \& Fredriksen-Goldsen, KI. 2012, 'Hispanic lesbians and bisexual women at heightened risk for health disparities', American Journal Public of Health, vol. 102, no. 1, pp. 9-15.

28. Kissil, K \& Davey, M 2012, 'Health Disparities in Procreation: Unequal Access to Assisted Reproductive Technologies', Journal of Feminist Family Therapy, vol. 24, pp. 197-212.
29. Lyons, A \& Hosking, W 2014, 'Health disparities among common subcultural identities of young gay men: Physical, mental, and sexual health', Archives of Sexual Behavior, vol. 43, pp. 1621-1635.

30. Lyons, A, Pitts, M \& Grierson, J 2012, 'Exploring the psychological impact of HIV: Health comparisons of older Australian HIV-positive and HIV-negative gay men', AIDS and Behavior, vol. 16, pp. 2340-2349.

31. Lyons, A, Pitts, M \& Grierson, J 2013, 'Methamphetamine use in a nationwide online sample of older Australian HIVpositive and HIV negative gay men', Drug and Alcohol Review, vol. 32, pp. 603-610.

32. Mays, VM \& Cochran, SD 2001, 'Mental health correlates of perceived discrimination among lesbian, gay, and bisexual adults in the United States', American Journal of Public Health, vol. 91, pp. 1869-1876.

33. Moosa-Mitha, M 2005, 'Situating anti-oppressive theories within critical and difference-centred perspectives. In Research as Resistance: Critical, Indigenous and Antioppressive Approaches Edited by: Brown L, Strega S. Toronto: Canadian Scholars' Press/Women's Press; pp. 37-72.

34. Morrison, MA 2011, 'Psychological health correlates of perceived discrimination among Canadian gay men and lesbian women', Canadian Journal of Community Mental health, vol. 30, pp. 81-98.

35. Mulé, NJ, Ross, LE, Deeprose, B, Jackson, BE, Daley, A, Travers, A \& Moore, D 2009, 'Promoting LGBT health and wellbeing through inclusive policy development'. International Journal for Equity in Health, vol. 8, no. 18.

36. Pereira, H \& Costa, PV 2016, 'Modeling the impact of social discrimination on the physical and mental health of Portuguese gay, lesbian and bisexual people', Innovation: The European Journal of Social Science Research, vol. 29, no.1, pp. 1-13.

37. Pereira, H \& Rodrigues, P 2015, 'Internalized homophobia and suicidal ideation among LGB youth', Journal of Psychiatry: Open Access, vol. 18, no. 2, pp.1-6.

38. Pereira, H 2014, 'Condom use and HIV-related behaviors in Portuguese men who have sex with men: A study of sexual behavior and sexual pleasure', Journal of AIDS and Clinical Research, vol. 5, no. 2, pp. 1-5.

39. Rankin, SR, Weber G, Blumenfeld W \& Frazer, S 2010, 2010 state of greater education for lesbian, gay, bisexual and transgender people, Campus Pride, Charlotte, NC.

40. Rivers, I 2001, 'The bullying of sexual minorities at school: Its nature and long-term correlates', Educational and Child Psychology, vol. 18, pp. 32-46.

41. Sabin, JA, Riskind, RG \& Nosek, BA 2015, 'Health care providers' implicit and explicit attitudes toward lesbian women and gay men', American Journal of Public Health, vol. 105, no. 9, pp. 1831-1841.

42. Sears, B \& Mallory, C 2011, Documented Evidence of Employment Discrimination \& Its Effects on LGBT People, The Williams Institute, Los Angeles. 
43. Semp, D \& Read, J 2015, 'Queer conversations: improving access to, and quality of, mental health services for samesex-attracted clients', Psychology \& Sexuality, vol. 6, no. 3, pp. 217-228.

44. Thoma, BC \& Huebner, DM 2013, 'Health consequences of racist and antigay discrimination for multiple minority adolescents', Cultural Diversity and Ethnic Minority Psychology, vol. 19, pp. 404-413.

45. Ward, BW, Dahlhamer, JM \& Galinsky, AM 2013, 'Sexual Orientation and Health Among U.S. Adults: National Health Interview Survey', National Health Stat Report, vol. 15, no. 77, pp. 1-10.

46. Whitehead, J, Shaver, J \& Stephenson, R 2016, 'Outness,
Stigma, and Primary Health Care Utilization among Rural LGBT Populations', PLoS ONE, vol. 11, no. 1, pp. e0146139.

47. Willoughby, BL, Lai, BS, Doty, ND, Mackey, ER \& Malik, NM 2008, 'Peer crowd affiliations of adult gay men: Linkages with health risk behaviors', Psychology of Men and Masculinity, vol. 9, pp. 235-247.

48. Wolitski, RJ \& Fenton, KA 2011, 'Sexual health, HIV, and sexually transmitted infections among gay, bisexual, and other men who have sex with men in the United States', AIDS and Behavior, vol. 15(Suppl. 1), pp. S9-S17.

49. Woodford, MR, Han, Y, Craig, S, Lim, C \& Matney, MM 2014, 'Discrimination and mental health among sexual minority college students: The type and form of discrimination does matter, Journal of Gay \& Lesbian Mental Health, vol. 18, pp. 142-163.

\section{ADDRESS FOR CORRESPONDENCE}

Henrique Pereira, Department of Psychology and Education \& Health Sciences Research Centre, University of Beira Interior Rua Marques D’Ávila e Bolama, 6200 - Covilhã, Portugal, E-mail: hpereira@ubi.pt 